\title{
Alejandro de Afrodisias, Acerca del intelecto. Traducción
}

\section{Alexander of Aphrodisias, On intellect. A translation}

\author{
José Manuel García VALVERDE \\ Universidad de Sevilla \\ jvalverde13@us.es
}

\section{Resumen}

En este artículo se ofrece una traducción anotada del De intellectu del filósofo aristotélico Alejandro de Afrodisias ( $f l$. aprox. 200 d.C.). También se incluye una breve introducción.

Palabras clave: Intelecto, alma, Aristóteles

\section{Abstract}

This paper offers a Spanish translation of Alexander of Aphrodisias' On intellect. Also one can find a short introduction to the text.

Keywords: Intellect, soul, Aristotle

\section{Introducción}

El tratado Acerca del alma de Alejandro de Afrodisias se ha creído compuesto en dos libros hasta el siglo XIX, cuando primero J. Freudenthal y posteriormente I. 
Bruns, el editor de la obra en el Supplementum aristotelicum II.1 (1887), pusieron en evidencia que lo que se transmitía en los manuscritos como libro segundo del tratado no constituía sino una miscelánea de escritos breves de temática variada entre los que abundaban cuestiones de carácter psicológico, pero también había otras de carácter ético y de carácter físico. El conjunto fue descrito ya por Freudenthal como un Supplementum al tratado principal o Mantissa (que significa literalmente «añadido» o «complemento»); posteriormente Bruns adoptó este último término y hoy es el más usado para designar este conjunto de escritos. Es, por otro lado, bastante improbable que el autor de estos escritos los hubiera reunido y les hubiera dado el orden con el que han llegado hasta nosotros. Muchos de ellos parecen estar vinculados a la actividad docente, ya que contienen bosquejos de razonamientos o indicaciones de cómo se debe polemizar en una cuestión determinada con otras escuelas filosóficas. No hay, pues, apenas pretensión estilística y, en la mayoría de los casos no leemos sino una concatenación de argumentos engarzados con el omnipresente éti («además», «aún»). Por otro lado, el texto presenta ciertas lagunas que dificultan su lectura e interpretación.

No obstante estas dificultades, el conjunto resulta interesante por varios motivos: en primer lugar, porque nos permite conocer de primera mano la actividad filosófica que se realizaba dentro de la escuela peripatética en la transición entre los siglos II y III de nuestra era; en segundo lugar, porque los escritos tienen en su mayoría una vertiente polémica que nos permite conocer la relación del aristotelismo con las otras escuelas de la época imperial; y, en tercer lugar, precisamente por lo que acabamos de mencionar, constituyen una rica fuente de información sobre esas otras escuelas filosóficas: de hecho, las modernas obras recopilatorias de la época helenística e imperial contienen un buen número de fragmentos extraídos de estos escritos.

Con respecto a la cuestión de la autenticidad de la Mantissa poco se puede decir. De su periplo editorial sólo conocemos lo que hemos adelantado al principio de esta introducción: los manuscritos transmiten el conjunto de estos escritos como libro segundo del tratado Acerca del alma, pero no sabemos si fueron editados como obra independiente, quizá después de la muerte de Alejandro, ni si fueron vinculados desde el principio a dicho tratado. Se ha señalado como indicio de inautenticidad el hecho de que algunos de esos escritos expresen puntos de vista que no parecen atribuibles a Alejandro o que directamente se oponen a lo que él sostiene en las otras obras. Sin embargo, esta posición es fácilmente rebatible si se tiene en cuenta que, dada la naturaleza miscelánea y dispar del conjunto, en algunos de esos escritos Alejandro podía estar simplemente reuniendo argumentos que él rechazaba, lo que podía tener una cierta funcionalidad pedagógica. Además, puesto que desconocemos la fecha de realización de los escritos, no es descartable que pertenecieran a distintas etapas de su pensamiento. Hoy, en general, no se pone en duda su autenti- 
cidad, y todas las ediciones modernas que se han realizado tanto del conjunto, como de algunas de sus partes, se presentan bajo el nombre de Alejandro de Afrodisias.

De los veinticinco escritos que componen la Mantissa el que más trascendencia ha tenido ha sido, sin duda, el que aparece en segundo lugar, un breve ensayo que trata la cuestión del intelecto y que ha atraído especialmente la atención de los filósofos medievales tanto desde el ámbito cristiano como desde el musulmán y judaico $^{1}$. Su interés radica, por un lado, en el hecho de que incluye una interpretación de la noética de Aristóteles (Acerca del alma III 4-5) y, por otro lado, en el de que, puesta en paralelo esta interpretación con la que se encuentra en el tratado Acerca del alma de Alejandro, pueden constatarse algunas divergencias significativas: la más importante se sitúa quizá en que aquí en la Mantissa el intelecto agente, que es igualmente identificado con la causa primera, interviene directamente en el comienzo del desarrollo intelectual de la persona. Esta importante divergencia y algunas otras han hecho que dentro de la crítica moderna haya habido quien se haya decantado por considerar que no pudo ser Alejandro el autor del De intellectu. Esta posición fue adoptada por P. Moraux en $1942^{2}$, aunque posteriormente él mismo la ha abandonado señalando que, si se sopesan bien las coincidencias doctrinales y las divergencias entre ambas obras, no hay inconveniente en que ambas obras pertenezcan a la misma pluma si bien en dos estados de madurez distintos ${ }^{3}$. El mismo P. Moraux sostiene, frente a B. Bazán y P. Donini, que el segundo escrito de la Mantissa pertenece a un período menos maduro que el tratado Acerca del alma, pues «ha precedido al gran comentario al De anima, mientras que el De anima personal de Alejandro resumiría los resultados alcanzados en el comentario» ${ }^{4}$. Más recientemente P. Accattino ha formulado la hipótesis de que el texto esté constituido por una serie de anotaciones hechas por el propio Alejandro para uso personal como recordatorio de la teoría aristotélica del voûs. Estas anotaciones estarían divididas en tres grandes bloques cuya yuxtaposición, realizada seguramente después de la muerte de Alejandro por alguien que tuvo acceso a sus escritos personales, ha dado lugar al texto que se ha conservado 5 .

\footnotetext{
${ }^{1}$ Se observan huellas de la influencia del tratado en al-Kindi, al-Farabí, Avicena y Averroes, y dentro de la cristiandad es prueba del interés que se tuvo en él el hecho de que, mientras que del tratado Acerca del alma no hay disponible una traducción latina hasta finales del siglo XV, ya desde el siglo XII puede leerse en latín el De intellectu: cf. M. Schroeder-R. B. TodD, Two Greek Aristotelian Commentators on the Intellect, Toronto, 1990, págs. 2-4.

2 Cf. P. Moraux, Alexandre d'Aphrodise, exégète de la Noétique d'Aristote, París, 1942, pág. 140.

3 Cf. P. Moraux, «Le De anima dans la tradition grecque. Quelques aspects de l'interprétation du traité, de Théophraste à Thémistius», en G. E. R. LloyD-G. E. L. OXen (eds.), Aristotle on Mind and the Senses. Proceedings of the Seventh Symposium Aristotelicum, Cambridge, 1978, págs. 281-324.

4 Ibidem pág. 305.

5 Cf. Alessandro di ApHrodisia, De intellectu, ed. P. Accattino, Turín, 2001, págs. 14-15.
} 
Estos tres bloques, por otro lado, se identifican con bastante claridad en el texto. El primero de ellos $(106,19-110,3)$ es una exposición de los tres estadios intelectivos: Alejandro parte de un estudio del intelecto material, más completo, por cierto, que el que desarrolla en su tratado Acerca del alma y termina planteando un buen número de consideraciones acerca del intelecto agente: la analogía de la luz, el intelecto agente como objeto de pensamiento, la inmortalidad y la autointelección de aquél, etc. La segunda parte $(110,4-112,4)$ trata el tema del voûs thýrathen (el intelecto venido de fuera al que se refiere Aristóteles en el tratado Acerca de la reproducción de los animales II 3, 736b27-29), al que Alejandro identifica con el intelecto agente. Esto da pie a que se vuelvan a tratar algunas cuestiones sobre la naturaleza de este intelecto: su faceta creadora de los inteligibles, su doble carácter de intelecto a la par que objeto intelectivo, la analogía de la luz otra vez, etc. Y finalmente la tercera parte $(112,5-113,24)$ se dedica primero a la exposición de una doctrina anónima (véase la nota 39 del texto) acerca de un intelecto inmanente al ámbito físico y posteriormente a su refutación.

La presente traducción del De intellectu, primera que se realiza al español, está basada en el texto griego de la edición crítica de R. W. Sharples ${ }^{6}$. Esta edición supera con creces la de I. Bruns por cuanto que contiene una revisión completísima de los manuscritos y de la tradición doxográfica. No obstante, hemos decidido conservar la paginación de referencia de la edición de I. Bruns, que es la única que se usa y que R. W. Sharples conserva en su propia edición. Por otro lado, hemos estado muy atentos a los distintos trabajos de P. Accattino sobre esta obra: entre otras aportaciones, ha realizado dos ediciones bilingües (griego-italiano) que nos han resultado de gran utilidad; la primera comprende tan sólo el De intellectu ${ }^{7}$ y la segunda todo el texto de la Mantissa ${ }^{8}$. Entre la versión de Accattino y la de Sharples hay algunas discrepancias: en un número limitado de ocasiones hemos preferido acogernos a las variantes defendidas por Accattino cuando nos han parecido más apropiadas para realizar una correcta lectura del texto9.

Han sido numerosas las traducciones que han recibido tanto el De intellectu en solitario (las más numerosas), como la Mantissa en su totalidad. Aquí sólo vamos a referir algunas de ellas 10: P. Moraux incorporó a su ya clásico Alexandre d'Aphrodise, exégète de la Noétique d'Aristote (1942) la traducción francesa del De intellectu (págs. 185-194). Este mismo escrito ha sido traducido en varias ocasiones

\footnotetext{
6 Alexander Aphrodisiensis, De anima libri mantissa. A new edition of the Greek text with introduction and commentary, ed. R. W. SHARPLES, Berlín-Nueva York, 2008.

${ }^{7}$ Cf. supra n. 5

8 Realizada con la colaboración de P. C. Ghiggia: Alessandro di Afrodisia, De anima II (Mantissa), Alessandria, 2005.

9 Véase la Nota de Crítica Textual.

10 Para un recuento más exhaustivo véase: AleXANDER of ApHrodisias, Supplement to On the Soul, ed. R. W. Sharples, Londres, 2004, pág. 24.
} 
al inglés: especialmente importante es el trabajo que realizaron F. M. Schroeder y R. B. Todd, en el que además de una traducción muy cuidadosa se incluye una introducción breve pero muy comprehensiva, y un comentario crítico muy completo11. Por otro lado, el mismo R. W. Sharples editó en 2004 una traducción completa de la Mantissa en el seno del proyecto que se realiza en la editorial inglesa Duckworth para publicar traducidos los comentarios antiguos a Aristóteles ${ }^{12}$. Ya hemos mencionado las traducciones de P. Accattino al italiano en sus ediciones bilingües del De intellectu y de la Mantissa. También se ha publicado la versión árabe medieval del De intellectu ${ }^{13}$, así como la traducción latina basada en esta versión y atribuida a Gerardo de Cremona ${ }^{14}$.

Nota de crítica textual Acerca del intelecto

\begin{tabular}{|c|c|c|}
\hline $\begin{array}{l}\text { Pasaje } \\
1.106,30\end{array}$ & $\begin{array}{l}\text { Lectura de Sharples } \\
\text { ở } \tau \varepsilon\end{array}$ & 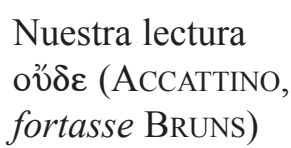 \\
\hline 2. 108,2 & $\alpha$ ¿ós & $\alpha$ $\alpha$ tó (ACCATTINO) \\
\hline
\end{tabular}

\section{Acerca del intelecto}

El intelecto, según Aristóteles, es triple: /20/ uno es, en efecto, el intelecto material, y digo «material» no porque sea él un substrato tal como la materia15 (pues llamo «materia» a un substrato capaz de llegar a ser una cosa particular gracias a la presencia de una forma), sino porque, como para la materia el ser materia consiste en su potencialidad para todo, en aquello en lo cual hay potencialidad también el ser en potencia es, en tanto que tal, material. De hecho, el intelecto que aún no está pensando, pero que es capaz de llegar a estarlo, es material, y /25/ tal facultad del alma es el intelecto material, el cual, si bien en la actualidad no es ninguna de las cosas existentes, es capaz de llegar a serlas todas: si es que es verdaderamente posible que

11 Cf. M. Schroeder-R. B. Todd, op. cit. págs. 1-74.

12 Véase la nota 10 de esta Introducción.

13 Cf. J. Finnegan, «Texte arabe du Peri Nou d'Alexandre d'Aphrodise», Mélanges de l'Université Saint Joseph 33 (1956), págs. 157-202.

14 Cf. G. Théry, Autour du décret de 1210, II: Alexandre d'Aphrodise: Aperçu sur l'influence de sa noétique, Kain, 1926.

15 Es posible que Alejandro esté aquí respondiendo a JENARCO DE CILICIA, aristotélico del siglo I a.C., quien sostenía que Aristóteles identificaba el intelecto con la materia prima por el hecho de que ambos son el lugar de las formas: cf. P. ACCATTino, Alessandro di Afrodisia: De intellectu, pág. 39.

16 En cuanto al intelecto material no hay diferencia entre lo que Alejandro dice aquí y lo que tenemos en el tratado Acerca del alma $(84,14-85,10)$, que es presumiblemente posterior: cf. P. MoRAux, Der Aristotelismus bei den Griechen, vol. III, págs. 386-394. 
existan intelecciones acerca de todo cuanto existe ${ }^{16}$. Pues lo que está destinado a ser receptivo de todas las cosas no debe ser en acto por su propia naturaleza ninguna de ellas. Y eso porque la intrusión de su propia forma en la recepción de las cosas que se encuentran fuera podría impedir los actos intelectivos sobre ellas. /30/ Tampoco los sentidos perciben aquellas cosas en las que consiste su propio ser, y por esta razón, la visión, que es capaz de percibir los colores, carece, por tanto, de color en el órgano en el cual ella se da y a través del cual obtiene la percepción: pues el agua carece de un color propio. |107| Es más, el sentido del olfato está hecho de aire (éste carece de olor), y es capaz de percibir los olores. El tacto, por su parte, no siente las cosas que son calientes o frías, duras o blandas en la medida en que lo son, sino las cosas que difieren en un grado mayor o menor ${ }^{17}$. Y esto es porque le sería imposible al tacto, en tanto que cuerpo, $/ 5 /$ carecer de esos contrarios: todo cuerpo que es natural y generado es, en efecto, tangible. En definitiva, tal como en el caso de los sentidos es imposible que el sentido que posea alguna cualidad sea capaz de percibir y discernir la cualidad que él posee, igualmente, dado que el intelecto es una cierta recepción y discernimiento de los inteligibles, no es posible que él sea ninguno de los objetos que discierne. En todo caso, tiene la capacidad de recibir todo cuanto existe, si es que puede pensarse todo. En consecuencia, /10/ el intelecto no es en acto ninguna de las cosas que existen, pero es potencialmente todas. Y esto es, en efecto, lo que significa para él ser intelecto 18 .

Las sensaciones, que se producen a través de cuerpos, no son idénticas a los objetos que perciben, sino que en acto son algo distinto: su facultad pertenece a un determinado cuerpo. Por esta razón, la percepción de los sensibles se da en tanto que el cuerpo es afectado de alguna manera. $Y$ esta es la causa por la cual ningún sentido puede percibirlo todo, /15/ ya que es él algo realmente en acto. Sin embargo, el intelecto, que no recibe las cosas existentes por medio de un cuerpo y que no es la facultad de un cuerpo, ni se ve afectado, no es en absoluto ninguna de las cosas que existen en acto ${ }^{19}$, ni siquiera es algo determinado dotado de capacidad, sino que es simplemente la facultad de un cierto tipo de entelequia y alma, capaz de recibir formas y pensamientos. Así pues, este intelecto, al ser material, existe en todos los seres que participan del /20/ alma perfecta, esto es, en los hombres 20 .

Otro intelecto es aquel que ya piensa, que tiene el hábito de pensar y que está en grado de tomar posesión, por su propia capacidad, de las formas de los objetos inteligibles, el cual es análogo a los artesanos que poseen el hábito y son capaces de realizar por sí solos los productos relativos a ese arte21. El intelecto primero, de

\footnotetext{
17 Es decir, difieren en cuanto a esas cualidades tal y como se dan en el propio órgano del tacto.

18 Cf. Aristóteles, Acerca del alma III 4, 429a18-27; AlejAndro, Acerca del alma 44,3; 84, 14-22.

19 Cf. Alejandro, Acerca del alma 84,21-22.

20 Cf. AlejAndro, Acerca del alma 84,26-28.

21 Cf. Aristóteles, Acerca del alma III 4, 429b5-9; Alejandro, Acerca del alma 86,1-5.
} 
hecho, no era como estos hombres, sino que era más bien como aquellos que son capaces de $/ 25 /$ adquirir un arte y llegar a ser artesanos. Y este intelecto es el intelecto material una vez que ha adquirido el hábito y también el pensar y el ser activo. Tal intelecto está presente en aquellos que han alcanzado una mayor perfección y piensan 22 . Éste es, entonces, el segundo intelecto.

Un tercer intelecto, además de los dos mencionados, es el intelecto agente /30/ por medio del cual el intelecto material deviene en hábito, y este intelecto agente es análogo -como dice Aristóteles 23 - a la luz. Pues como la luz resulta para los colores que son potencialmente visibles la causa de que lleguen a ser visibles en acto, así también este tercer intelecto hace del intelecto potencial y material intelecto en acto por el hecho de producir en éste un hábito que lo hace pensar. Ese intelecto es aquello que por su propia naturaleza es inteligible y es tal en acto $24:|\mathbf{1 0 8}|$ pues esto es productivo del pensar y lleva al intelecto material al acto. Por consiguiente, eso es en sí mismo intelecto, pues la forma inmaterial, que es la única que por su propia naturaleza es inteligible, es intelecto 25 . Y es que las formas insertas en la materia devienen inteligibles gracias al intelecto, siendo inteligibles en potencia. Pues el intelecto, por el hecho de separarlas de la materia /5/ con la que ellas tienen su ser, por sí mismo las hace inteligibles en acto, y entonces cada una de ellas, cuando es pensada, llega a ser en acto, por un lado, inteligible y, por otro, intelecto, aunque no eran tales antes y en virtud de su propia naturaleza. El intelecto en acto no es, en efecto, otra cosa que la forma pensada, de modo que cada una de estas formas, pese a que no es estrictamente inteligible, deviene intelecto al ser pensada. $\mathrm{Y}$ ello porque, igual que la ciencia en acto /10/ es idéntica al objeto de ciencia en acto, e igual que la sensación en acto es idéntica al sensible en acto y el sensible en acto es idéntico a la sensación en acto, así también el intelecto en acto es idéntico al inteligible en acto y el inteligible en acto es idéntico al intelecto en acto. El intelecto, en efecto, por el hecho de recibir la forma del objeto pensado y de separarla de la materia, $/ 15 /$ la hace inteligible en acto y llega a ser él mismo intelecto en acto.

De hecho, si un ente es por su propia naturaleza inteligible, y si es tal por sí mismo al ser inmaterial, no por obra de un intelecto que lo separa de la materia, entonces tal cosa es perpetuamente intelecto en acto. Pues el inteligible en acto es $/ 20 /$ un intelecto. Además, este inteligible por su propia naturaleza e intelecto en acto, el cual llega a ser la causa de que el intelecto material, por referencia a una tal

22 Cf. Alejandro, Acerca del alma 82,1-3.

23 Cf. ARIstóteles, Acerca del alma III 5, 430a15-17.

24 Comienza aquí la argumentación que conduce a la identificación del intelecto agente con el dios del libro XII de la Metafisica: cf. Alejandro, Acerca del alma 88,16-89,21.

25 Cf. ARISTÓteles, Acerca del alma III 5, 430a19-20: «Por lo demás, la misma cosa son la ciencia en acto y su objeto» (trad. de T. CALVO; B.C.G. 14, pág. 234).

26 P. ACCATTino sugiere que este mimeîsthai debe entenderse aquí con el sentido de «reproducir»: cf. Alessandro di Afrodisia: De intellectu, pág. 45. 
forma, separe, imite 26 y piense cada una de las formas inmersas en la materia y las vuelva inteligibles, es el intelecto agente, denominado «intelecto que viene de fuera» 27 , el cual no es una parte o una facultad de nuestra alma, sino que viene a existir en nosotros desde fuera siempre que lo pensamos, si es que el pensar se produce por la recepción de la forma $/ 25$ / y él es por sí mismo una forma inmaterial en el sentido de que nunca se ve acompañada por la materia, ni es separada de la materia al ser pensada 28 . Y como quiera que tenga él esta naturaleza, con razón está separado de nosotros por el hecho de que su ser intelecto no depende de que sea pensado por nosotros, sino que es tal por su propia naturaleza, en la medida en que es en acto intelecto e inteligible. Ahora bien, una tal forma es también una entidad incorruptible libre de materia. Por esta razón, además, aquello que es en acto desde fuera una tal forma es intelecto agente, /30/ con razón denominado «intelecto inmortal» $|\mathbf{1 0 9}|$ por parte de Aristóteles ${ }^{29}$. También todas las demás formas pensadas son intelecto cuando son pensadas, pero no son intelecto que exista fuera o venga de fuera, sino que llegan a ser tales cuando son pensadas. Sin embargo, puesto que este intelecto existe incluso antes de ser pensado, es razonable que, cuando ha sido pensado, sea y sea dicho «de fuera».

El intelecto en hábito, cuando está activo, puede pensarse a sí mismo, /5/ no en tanto que es intelecto (pues entonces el pensar y el ser pensado le pertenecerían simultáneamente y respecto al mismo objeto), sino, de hecho, en tanto que el intelecto en acto es idéntico a los objetos pensados en acto ${ }^{30}$. Por consiguiente, al pensarlos, se piensa a sí mismo, si es que esos objetos que piensa llegan a ser intelecto a consecuencia de ser pensados. Y es que, si los objetos pensados son el intelecto en acto y éste piensa estos objetos, llega a pensarse a sí mismo. De hecho, cuando piensa, resulta idéntico a los objetos pensados; /10/ pero cuando no piensa, es distinto de ellos. Así se podría decir que la percepción también se percibe a sí misma

27 Cf. ARISTÓTeles, Reproducción de los animales II 3, 736b27-29; AlEJANDRo, Acerca del alma 90,19 .

28 Frente a lo que tenemos en el tratado Acerca del alma de Alejandro, en donde no llega a explicarse con claridad el tipo de causalidad que el intelecto agente, esto es, Dios ejerce sobre el intelecto humano, aquí se aborda la cuestión con cierto detalle: el intelecto humano, que empieza siendo una pura potencialidad para recibir las formas inteligibles, en un determinado momento del desarrollo de un individuo recibe del exterior, mediante un acto de pensamiento, esa forma pura que no requiere de nada más que de sí misma para existir y que es por sí misma inteligible: esta forma pura, que por ser inteligible en acto es intelecto, desempeña un papel productivo con respecto al propio acto de pensamiento humano, pues le confiere a nuestro intelecto el hábito de pensar. Este hábito, por otro lado, consiste en la abstracción de la forma separándola de la materia que le sirve de substrato. Sin embargo, esta actividad que desarrolla la inteligencia humana no puede realizarse a menos que se tenga ese primer pensamiento que tiene por objeto a Dios, el cual es condición necesaria de todos los demás pensamientos.

29 Cf. ARISTÓteles, Acerca del alma III 5, 430a23.

30 Cf. Aristóteles, Acerca del alma III 4, 429b9. 
cuando percibe los objetos que llegan a ser en acto idénticos a ella. Pues, como hemos dicho ${ }^{31}$, la percepción en acto es también el objeto percibido: en efecto, la sensación y el intelecto, mediante la recepción de las formas separadas de la materia, toman los objetos que les corresponden. Es más, podría decirse /15/ que el intelecto se piensa a sí mismo no en tanto que intelecto, sino en tanto que es él mismo inteligible, pues se recibirá a sí mismo como un inteligible, al igual que cualquier inteligible, no como intelecto. El ser inteligible es, en efecto, una propiedad del intelecto, pues al ser él por sí mismo también uno de los entes y no ser objeto de percepción, lo que le queda es ser inteligible. Y ello porque, si fuera pensado por sí mismo como intelecto y en tanto que es intelecto, /20/ no podría pensar otra cosa que lo que es intelecto: como consecuencia de ello tan sólo se pensaría a sí mismo. Pero, puesto que piensa los inteligibles que no son intelecto antes de ser pensados, entonces también se piensa a sí mismo como este tipo de cosas, es decir, como uno cualquiera de los inteligibles. Se sigue que este intelecto, que procede del intelecto material, se piensa a sí mismo de forma accidental. Y también el primer intelecto e intelecto en acto se piensa a sí mismo de forma similar /25/ y por la misma causa. Sin embargo, él tiene una ventaja sobre este intelecto nuestro, ya que él no piensa otra cosa que a sí mismo. Puesto que es inteligible se piensa a sí mismo, y puesto que es inteligible en acto y por su propia naturaleza él siempre será pensado, obviamente por parte de aquel que piensa $<$ siempre $>32$ en acto: pero sólo él es un intelecto que está siempre pensando en acto, por lo que siempre se pensará a sí mismo. Y sólo a sí mismo, pues es simple33: en efecto, el intelecto simple piensa un objeto simple y no hay ningún otro inteligible simple excepto él mismo. /30/ Pues este intelecto no está mezclado, es inmaterial y no tiene en sí mismo potencialidad alguna. Así pues, sólo se pensará a sí mismo. En consecuencia, en tanto que él es intelecto, se pensará a sí mismo como inteligible, pero en tanto que es $|\mathbf{1 1 0}|$ en acto intelecto e inteligible, se pensará a sí mismo perpetuamente, y en la medida en que es el único que es simple, tiene la capacidad de pensar algo simple, y él es en sí mismo el único simple entre los inteligibles.

\footnotetext{
31 Cf. supra $108,10$.

32 Añadido de J. Freudenthal en base a un texto del comentario a la Metafísica del pseudo-Alejandro (ed. M. HAYDUCK en Com. in Arist. Gr. I, pág. 699,4). I. Bruns lo conservó.

33 Este término haploûs para designar al intelecto agente no aparece en la noética que Alejandro desarrolla en su tratado Acerca del alma, lo que a juicio de F. M. Schroeder puede servir de argumento en contra de la atribución de esta obra a Alejandro de Afrodisias: cf. F. M. Schroeder-R. B. Todd, Two Greek Aristotelian Commentators on the Intellect, Toronto, 1990, pág. 68.

34 Ékousa dè perì vồ tô̂ thýrathen parà Aristotélous, hà diesōsámēn. La identificación de este Aristóteles ha constituido un interesante debate en la crítica moderna. Podemos ordenar de manera resumida los distintos puntos de vista así: (1) Eduard Zeller (Die Philosophie der Griechen in ihrer geschichtlichen Entwicklung, vol. III.3, Leipzig, 1909, pág. 815 n. 3) optó por enmendar el texto sus-
} 
Y he escuchado acerca del intelecto que viene de fuera de Aristóteles la doctrina que he mantenido en mi memoria ${ }^{34}$. /5/ Las consideraciones que movieron a Aristóteles a introducir el intelecto venido de fuera se ha dicho que son las siguientes: la analogía extraída de los sensibles y la extraída de todo aquello que es generado. $Y$ es que igual que en todas las cosas que se generan hay algo que padece, algo que es productivo y en tercer lugar algo que se genera a partir de esas cosas (y de manera similar en el caso de sensibles: pues el órgano del sentido es pasivo, el sensible es productivo y lo que se genera es /10/ la percepción del sensible a través del órgano del sentido), de la misma manera, también en el caso del intelecto, él sostenía que ha de existir un intelecto agente que podrá conducir al intelecto potencial y material a la actividad (su actividad consiste en volver para sí mismo inteligible todo cuanto existe). Pues, tal como existen sensibles que <estando ellos mismos $>$ en acto producen la sensación en acto, así también ha de haber ciertas cosas que, siendo ellas misma inteligibles en acto, $/ 15 /$ hacen que el intelecto sea tal: pues no es posible que algo produzca algo si no está en acto. Ahora bien, ninguno de los

tituyendo Aristotélous por Aristokléous, refiriéndose a Aristocles de Mesene. Hoy se rechaza generalmente esta suposición por su falta de fundamento histórico y textual. (2) En 1942 Paul Moraux (Alexandre d'Aphrodise, exégète de la Noétique d'Aristote, París, 1942, pág. 148) señalaba que el Aristóteles del texto era el fundador de la escuela, de modo que el «he escuchado de Aristóteles» no debía entenderse en el sentido literal de «he escuchado de boca de Aristóteles» sino en uno más laxo en el que el autor se refería a una tradición que se remontaba hasta Aristóteles de Estagira. (3) El mismo Moraux cambió de parecer dos décadas más tarde («Aristoteles, der Lehrer Alexanders von Aphrodisias», Archiv für Geschichte der Philosophie 49 (1967), págs. 169-182): consideró entonces que la verdadera identidad de aquel Aristóteles no era la del fundador, sino la de un Aristóteles de Mitilene, maestro de Alejandro. Varios especialistas han aceptado posteriormente este parecer, pero también ha habido detractores, uno de los cuales es el especialista francés P. Thillet, quien en la introducción de su edición del tratado Acerca del destino rebate los argumentos de Moraux (AlEXANDRE D’APHRODISE, Traité du destin, París, 1984, págs. XI-XXXII); en lo tocante al texto citado señala que es poco comprensible que el mismo nombre concurra dos veces en el espacio de un par de líneas con referencia a dos personas diferentes sin que Alejandro se hubiese preocupado de especificar de algún modo las identidades. (4) Recientemente se ha insistido en la hipótesis de que esos dos «Aristóteles» se refieren al mismo Aristóteles de Estagira. En este parecer han coincidido varios especialistas como M. Schroeder, R. B. Todd (M. Schroeder-R. B. TodD, Two Greek Aristotelian Commentators on the Intellect, Toronto, 1990, págs. 22-31) o R. W. Sharples (J. OpsOMER-R. W. Sharples, «Alexandre of Aphrodisias, De intellectu 110.4: 'I heard this from Aristotle'. A Modest Proposal», Classical Quarterly 50.1 (2000) págs. 252-256). Dejando a un lado ciertos matices que diferencian estas interpretaciones, podemos señalar un punto de coincidencia en el hecho de que se considera el parà Aristotélous no como complemento del verbo sino del perì vôu toû thýrathen, de modo que en vez de «he escuchado de Aristóteles acerca del intelecto que viene de fuera la doctrina que he mantenido en mi memoria» se propone «he escuchado acerca del intelecto que viene de fuera de Aristóteles la doctrina que he mantenido en mi memoria». En favor de esta interpretación hay varios argumentos de peso: en primer lugar, no es necesario realizar una modificación textual (Schroeder-Todd proponen la inserción de un artículo $<$ tà $>$ perì vô̂ tô̂ thýrathen que Sharples con buen criterio, a nuestro juicio, no considera necesaria), y en segundo lugar, se salva la dificultad de suponer dos sujetos distintos para un mismo nombre que aparece repetido casi de inmediato y sin marca alguna de distinción. 
objetos que pensamos es un inteligible en acto, y ello porque nuestro intelecto piensa objetos sensibles, que son potencialmente inteligibles, y éstos, a su vez, llegan a ser inteligibles por obra del intelecto. Ésta es, en efecto, la actividad del intelecto: separar y abstraer por su propio poder objetos sensibles en acto a partir de aquellas determinaciones cuya presencia los hace sensibles, $/ 20 /$ y definirlos por ellos mismos. Si, de hecho, ésta es la actividad del intelecto que previamente existía en potencia, y si es necesario que aquello que llega a la existencia y es conducido de la potencia al acto logre la existencia por obra de algo que existe en acto, entonces debe haber también un intelecto que sea agente en acto, el cual hará que lo que hasta ese momento estaba en potencia pueda ser activo y pensar. De esta naturaleza es el intelecto que viene de fuera. Éstas, pues, son las razones que motivaron a /25/ aquél 35 .

En consecuencia, habrá algo que sea, de hecho, inteligible en acto, siendo tal por su propia naturaleza, igual que, por otro lado, hay también un sensible que no llega a ser tal por obra de la sensación. Esto es un intelecto, una determinada naturaleza y una entidad cognoscible para ninguna otra cosa más que para el intelecto. Y ello porque no es ciertamente un sensible, y porque tampoco todos los inteligibles llegan a ser tales gracias a nuestro intelecto sin ser inteligibles por su propia naturaleza; /30/ por el contrario, hay algo que es de hecho en sí mismo inteligible, en tanto que lo es por su propia naturaleza. Éste es ese verdadero objeto que el intelecto en potencia piensa cuando se perfecciona y se desarrolla. Pues igual que la capacidad de andar que el hombre posee tan pronto como viene a la existencia es llevada al acto con el pasar del tiempo y sin que alcance su perfección por causa de algún tipo de afección, |111| de la misma forma el intelecto, una vez que ha sido llevado a la perfección, también piensa los inteligibles por naturaleza y convierte para sí en inteligibles las cosas sensibles, precisamente porque es activo ${ }^{36}$. Y es que el intelecto no es por su propia naturaleza pasivo de tal manera que se constituya y sea afectado por otra cosa, como le pasa a la sensación. Más bien, al contrario. En efecto, mientras que la sensación se produce por una afección, ya que ella es algo pasivo y para ella la percepción /5/ se produce a través de una afección, el intelecto es algo productivo. Siendo, en efecto, capaz de pensar, al mismo tiempo deviene también artífice de la mayor parte de los inteligibles para alcanzar su intelección, a menos que alguien quiera decir, a este respecto, que el intelecto también es pasivo en el sentido de que él es receptivo de las formas. Después de todo, el recibir parece ser padecer, y el intelecto en verdad tiene esto en común con la sensación. Ahora

\footnotetext{
35 Es decir, al Aristóteles de la pág. 110,4.

36 La misma analogía del caminar es usada por Alejandro en los tratados Acerca del alma 82,5-10, y Acerca del destino 110,31-33. No obstante, en el tratado Acerca del alma dice justo lo contrario de lo que tenemos aquí, es decir, que el desarrollo de la capacidad intelectiva no es comparable al del caminar.
} 
bien, puesto que cada uno de los dos es caracterizado y definido /10/ no por eso que tienen en común con otra cosa, sino por lo que les es propio, entonces lo que el intelecto tiene en común con la sensación deberá ser caracterizado por lo que le es propio. En consecuencia, si la receptividad de las formas es común a él y a la sensación -si bien no de la misma manera-, pero él es productivo de esas formas que recibe, habrá de ser definido, más bien, en base a su hacer. Por lo tanto, el intelecto deberá ser algo activo, /15/ no algo pasivo. Por lo demás, el producir es para él anterior y esencial. Pues él primero produce un inteligible por abstracción y después por esta vía recibe una de las cosas que piensa y que define como una cosa determinada ${ }^{37}$. En efecto, aunque él separa y recibe al mismo tiempo, sin embargo se supone prioritario el separar: esto, al fin y al cabo, es lo que le permite a él recibir la forma. Y así como nosotros decimos que el fuego es sumamente productivo en el sentido de que consume $/ 20$ / y reduce a alimento suyo toda la materia que recibe (de hecho él es afectado en la medida en que se nutre), de la misma manera el intelecto que está en nosotros debe ser también considerado como productivo, pues él hace inteligibles las cosas que no son inteligibles en acto. Ninguna otra cosa es, en efecto, inteligible excepto el intelecto que existe en acto y por sí mismo. Y las cosas que llegan a ser inteligibles por obra de quien piensa, así como las actividades de éste, son ellas mismas también intelecto cuando son pensadas. Por lo tanto, si no existiera el intelecto, nada sería inteligible: /25/ ni el intelecto por naturaleza (en realidad, éste sería el único de tal naturaleza), ni tampoco aquello que deviene inteligible por gracia de ése 38 : si él no existiera tampoco podría ser productivo.

El intelecto que existe por naturaleza y viene de fuera habrá de resultar colaborador del intelecto que se encuentra en nosotros, pues las otras cosas, por más que sean inteligibles en potencia, no serían inteligibles si no hubiese algo que fuese inteligible por su propia naturaleza. De hecho, este objeto que es inteligible por su propia naturaleza $/ 30 /$, y que llega a estar presente en quien piensa por el hecho de haber sido pensado, es un intelecto que se ha hecho presente en quien piensa, que es pensado desde fuera, que es inmortal y que infunde en el intelecto material el hábito de pensar los inteligibles en potencia. Pues igual que la luz, que es producti-

\footnotetext{
37 Según se ha dicho anteriormente (cf. supra 108,3-4; 14-15; 110,19-20), la abstracción consiste en la actividad intelectual que separa las formas de la materia. De esta manera se obtiene las especies inteligibles, las cuales le permiten al intelecto humano, una vez que las tiene en su poder, identificar una cosa particular como perteneciente a una especie determinada. En la pág. 110,20 este proceso ha sido definido como horísasthai kath'hautá, es decir, «definir [los sensibles] por sí mismos». Cf. AlEJANDRO, Acerca del alma 84,19-21.

38 P. AcCattino (cf. Alessandro di Afrodisia: De intellectu pág. 54) sugiere que este toútou debe referirse al intelecto humano. No hay, en efecto, en esta obra ninguna manifestación que implique que el intelecto divino produce directamente los inteligibles; por el contrario, él es el que habilita a nuestro intelecto para que realice ese proceso de abstracción que tiene como resultado la captación de la forma inteligible: cf. supra n. 37.
} 
va de la visión en acto, es ella misma vista y las cosas que con ella están, y a través de ella es visto el color, de la misma manera también el intelecto que viene de fuera deviene para nosotros la causa del pensar por ser pensado también por nosotros, no por $/ 35 /$ producir el propio intelecto, sino porque, gracias a su propia naturaleza, perfecciona el intelecto que existe y lo conduce hacia los objetos suyos propios. En consecuencia, el intelecto es por su naturaleza inteligible, mientras que los otros inteligibles lo son por el |112| arte de este intelecto y son sus productos, los cuales son producidos por el intelecto en potencia no porque se haya visto afectado o haya alcanzado su existencia por obra de algo (él era, después de todo, intelecto incluso antes de llegar a ser activo), sino porque se ha desarrollado y alcanza su perfección. Una vez que ha alcanzado su perfección, piensa los inteligibles por naturaleza y los que son debidos a su propia actividad y arte. Peculiar del intelecto es, en efecto, la capacidad de producir, y el pensar para él es actuar y no padecer.

/5/ Con la intención 39 de mostrar que el intelecto es inmortal y de escapar de los problemas que achacan al intelecto que viene de fuera, ya que necesita cambiar de lugar y no puede, si de verdad es incorpóreo, ni estar en un lugar ni cambiar de lugar, y estar ahora en un lugar y después llegar a estar en otro ${ }^{40}$, en virtud de una concepción suya propia él sostenía las mismas cosas respecto al intelecto del que se dice que existe en todo cuerpo mortal. /10/ Precisamente ha afirmado que el intelecto está en la materia como una entidad en una entidad, y que existe en acto por realizar sus actividades propias perpetuamente. Por lo que, cuando del temperamento del cuerpo se genera fuego o cualquier cosa del género de la mezcla con el resultado de que ello puede servir de instrumento para este intelecto que existe en esa mezcla (puesto que está en todo cuerpo y también esa mezcla es un cuerpo), este instrumento es denominado /15/ «intelecto en potencia», el cual se realiza sobre esa cualificada mezcolanza de cuerpos con la finalidad de recibir el intelecto en acto. Cuando éste se apodera de ese instrumento, en ese momento es activo como a través

\footnotetext{
39 Se inicia aquí la última parte de este escrito caracterizada por un abrupto comienzo que introduce de nuevo la cuestión del noûs thýrathen. Alejandro presenta en primer lugar la tesis de un autor anónimo acerca de esta cuestión y finalmente la refuta. La identidad de dicho autor es incierta: P. Accattino avanza la hipótesis de que se trate del mismo personaje que aparece en la pág. 110,4 (cf. Alessandro di Afrodisia: De intellectu págs. 10-15). Por su parte, F. M. Schroeder y R. B. Todd (cf. Two Greek Aristotelian Commentators on the Intellect págs. 26, 31 y 72) consideran que este fragmento es un añadido mal engarzado con el texto precedente y que la identidad del autor cuyos puntos de vista se expresan a continuación se ha perdido en una laguna del texto (la misma opinión que expresó ya P. Moraux en su primitivo Alexandre d'Aphrodise... pág. 149). Por otro lado, P. Moraux consideró más tarde que la figura que se esconde detrás de este fragmento no es otra que la de Aristóteles DE Mitilene, el presumible maestro de Alejandro: cf. «Aristoteles, der Lehrer Alexanders von Aphrodisias», págs. 169-182.

40 Esta objeción tiene presumiblemente una raíz platónica y, en efecto, la encontramos entre las dificultades movidas por el platónico Ático para entender la naturaleza del intelecto (cf. fr. 7,75 y ss., ed. E. Des Places).
} 
de un instrumento, como en relación a una materia y como por medio de la materia, y es entonces cuando se dice que pensamos. Y es que nuestro intelecto está compuesto de la potencialidad que es instrumento del intelecto divino (instrumento que Aristóteles /20/ llama «intelecto en potencia»), y de la actividad de aquél: si cualquiera de las dos cosas está ausente, es imposible que nosotros pensemos. Y justo tras el primer depósito del semen el intelecto en acto está presente, pues penetra en todas las cosas y existe en acto, tal como se da en cualquier cuerpo que se precie. Y cuando está activo a través de nuestra facultad, entonces se dice que es nuestro intelecto y que nosotros $/ 25 /$ pensamos, como si uno se imaginara a un artesano que en su arte algunas veces es activo sin instrumentos, y otras veces con instrumentos, precisamente cuando se produce la actividad de su arte sobre la materia. De la misma manera también el intelecto divino está perpetuamente activo (ésta es la causa por la cual existe en acto) y es activo a través de un instrumento cuando un tal instrumento surge de la combinación y del correcto temperamento de los cuerpos. /30/ Y ello porque en ese momento realiza una actividad material, y éste es nuestro intelecto. Y se separa de nosotros del mismo modo en que se une. No es que estando en un lugar cambie a otro, sino que, por estar en todas partes, permanece incluso $|\mathbf{1 1 3}|$ en el cuerpo disuelto tras la separación cuando se corrompe lo que tiene capacidad instrumental: tal como el artesano, después de haber soltado sus instrumentos, es incluso entonces activo, pero no en una actividad material e instrumental. De hecho, él decía que si es absolutamente necesario sostener que para Aristóteles el intelecto es divino e incorruptible, debemos pensar en él de esta manera y no de otra. Decía que hay que adaptar el pasaje del libro III Acerca del alma a estas explicaciones y que hay que /5/ referir el hábito y la luz a este intelecto que está en todas partes ${ }^{41}$.

$\mathrm{Y}$ ese intelecto o bien administra las cosas de aquí por sí mismo en relación con las traslaciones de los cuerpos divinos en lo alto, y las compone y las descompone, de tal manera que él mismo es también el artífice del intelecto en potencia, o bien hace eso en concierto con el movimiento regular de los cuerpos celestes. Las cosas de aquí se generan, en efecto, por obra /10/ de este movimiento, especialmente mediante el acercamiento y el alejamiento del sol: o bien se generan por obra del sol y del intelecto que está aquí, o bien la naturaleza se genera por obra de los cuerpos celestes y de su movimiento, mientras que ella por sí misma administra las cosas individuales junto con el intelecto.

Me parecía que a estas explicaciones se oponían, por un lado, el hecho de que el intelecto, a pesar de ser divino, esté presente incluso en las cosas más bajas, como han sostenido los estoicos; por otro lado, el hecho de que exista en general en las cosas de aquí un intelecto y una cierta guía providente $/ 15 /$ (y el hecho de que la providencia para las cosas de aquí abajo se produzca a través de la relación con los

41 Cf. ARISTÓteles, Acerca del alma III 5, 430a15. 
cuerpos divinos); y, por otro lado, el hecho de que el pensar no dependa de nosotros, ni tampoco sea obra nuestra, sino que desde el momento de nuestro nacimiento subsista en nosotros por naturaleza la concreción del intelecto potencial e instrumental, y la actividad provocada por el intelecto que viene de fuera.

$\mathrm{O}$, más bien, aquello que llega a existir en alguien por el hecho de ser pensado no cambia de lugar, pues tampoco las /20/ formas de los objetos sensibles, cuando los percibimos, vienen a existir en los órganos del sentido como lugares de ellas. Y al intelecto que viene de fuera se le dice «separado» y «que se separa» de nosotros no por el hecho de irse a algún sitio y cambiar de lugar, sino que está separado en cuanto que existe por sí mismo y no en unión de la materia; y se separa de nosotros por el hecho de no ser pensado, no porque se marche. Pues así es como llegaba a estar en nosotros también.

José Manuel García Valverde

Universidad de Sevilla

jvalverde13@us.es 